\title{
Liverpool Aortic Surgery Symposium V New Frontiers in Aortic Disease and Surgery
}

\author{
Mohamad Bashir, MD MRCS*, Matthew Fok, MBChB, Matthew Shaw, MS, Mark Field, FRCS, \\ Manoj Kuduvalli, FRCS, Michael Desmond, FRCA, Deborah Harrington, FRCS, \\ Abbas Rashid, FRCS, Aung Oo, FRCS \\ Liverpool Heart and Chest Hospital, Liverpool, United Kingdom
}

\begin{abstract}
Aortic aneurysm disease is a complex condition that requires a multidisciplinary approach in management. The innovation and collaboration among vascular surgery, cardiothoracic surgery, interventional radiology, and other related specialties is essential for progress in the management of aortic aneurysms. The Fifth Liverpool Aortic Surgery Symposium that was held in May 2013 aimed at bringing national and international experts from across the United Kingdom and the globe to deliver their thoughts, applications, and advances in aortic and vascular surgery. In this report, we present a selected short synopsis of the key topics presented at this symposium.

Copyright ๑ 2014 Science International Corp.
\end{abstract}

\section{Key Words}

Aortic Surgery · Conference · Aneurysm

\section{Introduction}

Aortic aneurysm disease is a complex condition that requires a multidisciplinary approach in management. The innovation and collaboration among vascular surgery, cardiothoracic surgery, interventional radiology, and other related specialties is essential for progress in the management of aortic aneurysms. The Fifth Liverpool Aortic Surgery Symposium that was held in May 2013 aimed at bringing national and international experts from across the United Kingdom

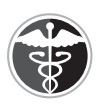

Fax +1 2037853346

E-Mail: aorta@scienceinternational.org

http://aorta.scienceinternational.org (c) 2014 Aorta.

Published by Science International Corp. ISSN 2325-4637

Accessible online at:

http://aorta.scienceinternational.org and the globe to deliver their thoughts, applications, and advances in aortic and vascular surgery. The program was organized into eight sessions from experts in aortic surgery over the two day period; the key points and sessions are listed in Table 1 and Table 2. There were discussions on a wide range of topics related to thoracic and abdominal aortic aneurysms, aortic dissections, genetics pertaining to the aorta, interventional radiology, endovascular therapy, intensive care, and anesthesiology and spinal cord protection. The symposium was an excellent opportunity to highlight the advances of aortic surgery and to discuss the future of aortic aneurysm management.

In this report, we present a selected short synopsis of the key topics which were raised throughout the two consecutive days of the symposium.

\section{Thoracic Aortic Surgery}

\section{Aortic Root Session}

Stentless versus Stented BioValsalva Graft. The increasing age of patients, recognition of anticoagulation-related complications, reduction in risk of repeated procedures of patients undergoing aortic root surgery, and the data that support the use of biological aortic valve in younger individuals have significantly increased the need for a composite biological valve conduit. Mr. Oo highlighted the concept of

${ }^{*}$ Corresponding author:

Mohamad Bashir, MD, MRCS

Thoracic Aortic Aneurysm Service

Liverpool Heart and Chest Hospital

Thomas Drive

Liverpool, L14 3PE, UK

Tel: + 44151600 1616, Fax: + 440151600 1862, E-Mail: drmbashir@mail.com 


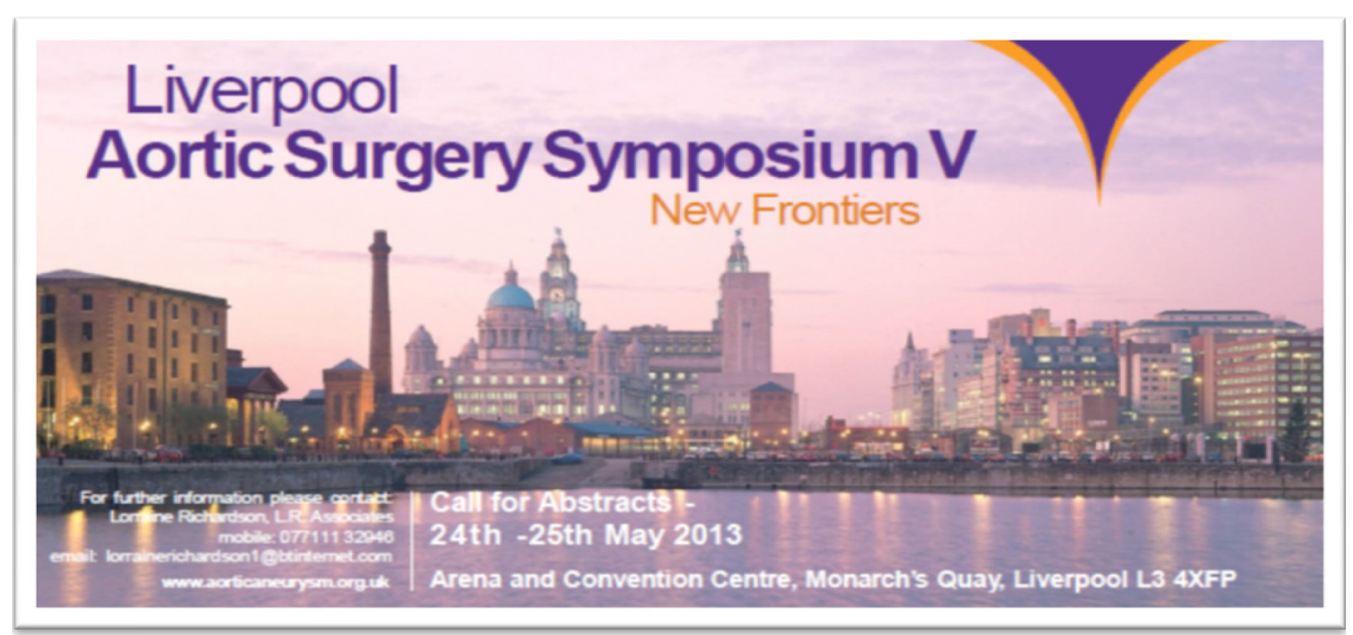

"patient tailored judgment" in selecting the appropriate biological valve conduit based on size of annulus, size of distal ascending aorta or arch or descending thoracic aorta, degree of calcification and deformity of aortic annulus, orientation of coronary ostia and buttons, degree of adhesions, and quality of periaortic root tissue. The BioValsalva valve conduit (Vascutek Terumo, Renfrewshire, Scotland, UK) is a presewn device combining an innovative trilaminate graft material with the Elan porcine stentless biological valve $[1,2]$. This was subsequently followed by the introduction of the stented BioValsalva Biplex. This conduit comprises an Aspire porcine stented valve and Biplex Valsalva graft. Mr. Oo highlighted the technical details of both conduits and discussed their advantages and disadvantages. The ready-to-use Triplex Valsalva Graft combines the advantages of a biological valve conduit with the advantages of a better leaflet dynamic, and less tension on coronary ostia. However, Mr. Oo highlights cautions in using the BioValsalva graft, which include the use of BioValsalva in patients with bicuspid aortic valve where ectatic coronary ostia position is common, the lack of $29 \mathrm{~mm}$ size, and fixed and relatively narrow area of tube graft in between porcine aortic posts for coronary buttons. He emphasized the importance of knowledge of the size of valve and size of graft in each conduit. He pointed out that it is imperative to avoid deforming the sewing ring, or twisting of the graft, as these can lead to aortic regurgitation. He also stressed the fact that the Triplex conduit has flammable graft material; use of cautery on the graft is contraindicated.

\section{Aortic Dissection Session}

Reintervention on Aortic Root and Following Type A Aortic Dissection. Reoperative surgery on the aortic root and ascending aorta continues to challenge cardiac surgeons. The mortality rate associated with these complex reconstructions is at least 3 times higher than it is for the initial surgery [3]. Complications after such procedures also occur with disappointingly high frequency, leading to substantial morbidity and delayed recovery [3]. At the symposium, redo aortic root replacement and reintervention following Type A dissection repair were discussed. The indications and outcomes for reoperative surgery on the aortic root vary considerably in the literature. Table 3 summarizes the indications in the literature for redo aortic root replacement based on series of heterogeneous case reviews [4-11]. The operative mortality ranges from $3 \%$ to $18 \%$ with 10 year survival around $60 \%$ and freedom from reoperation around $90 \%[7,9,11]$. Repair of acute Type A dissection (ATAD) is usually done in the urgent or emergency setting. The aim of the operation is mainly to address the pathology, which is of immediate threat to the life of the patient. This usually leaves residual dissected aorta behind, on many occasions proximally to the repaired aortic root and on many occasions distally at the arch and the descending thoracic and abdominal aorta. The residual aorta requires active monitoring with serial imaging modalities, as the need for reintervention on the proximal aorta averages approximately $30 \%$ and in the distal aorta approximately $20 \%$, though there is a fairly wide variation of this incidence 
Table 1. Fifth Liverpool Aortic Surgery Symposium: Key Points

\begin{tabular}{|c|c|c|}
\hline Topic & Presenter & Key Point \\
\hline Aortic Root Session & Mr. Aung Oo & $\begin{array}{l}\text { Three biological valved conduits are available in Europe } \\
\text { (but not in U.S.): } \\
\text { Biovalsalva } \\
\text { Biplex Valsalva } \\
\text { Triplex Valsalva Graft } \\
\text { Note: Cautery is contraindicated for the flammable Triplex } \\
\text { Valsalva Graft. }\end{array}$ \\
\hline Aortic Dissection Section & Mr. Manoj Kuduvalli & $\begin{array}{l}\text { Reoperation is necessary in many patients after life-saving } \\
\text { operations for acute Type A aortic dissection: } \\
\text { For } 30 \% \text { of patients proximally } \\
\text { For } 20 \% \text { of patients distally } \\
\text { Mortality for reoperations ranges from } 3 \text { to } 18 \% \text {. }\end{array}$ \\
\hline Aortic Arch Section & (Multiple) & $\begin{array}{l}\text { Technical approaches and current options reviewed fully. } \\
\text { The optimal technique for cerebral protection remains to } \\
\text { this day uncertain. }\end{array}$ \\
\hline & Dr. Roberto DiBartolomeo & $\begin{array}{l}\text { Elephant trunk procedure facilitates proximal anastomosis } \\
\text { of second-stage procedure. }\end{array}$ \\
\hline & Dr. Malakh Shrestha & $\begin{array}{l}\text { Second-stage procedure carries cumulative mortality risk } \\
\text { of stage } 1 \text { and stage } 2 \text {, as well as risk of spinal cord } \\
\text { injury. }\end{array}$ \\
\hline & & $\begin{array}{l}\text { Frozen elephant trunk procedure was developed to } \\
\text { mitigate these risks. }\end{array}$ \\
\hline Spinal Cord Protection & Dr. Randall Griepp & $\begin{array}{l}\text { Extensive research disputes the concept of a critical } \\
\text { artery of Adamkiewicz, in favor of a rich potential } \\
\text { collateral network of small vessels. }\end{array}$ \\
\hline Neuromonitoring & Dr. Mike Desmond & $\begin{array}{l}\text { MEP monitoring can be extended for several days in ICU, } \\
\text { permitting early recognition of late-onset paraplegia. }\end{array}$ \\
\hline Thoracoabdominal Aneurysms & Mr. Aung Oo & $\begin{array}{l}\text { When the aorta can be clamped proximally for the upper } \\
\text { anastomosis, LA-FA bypass is used. } \\
\text { When proximal clamping is not possible, the procedure is } \\
\text { done under DHCA. }\end{array}$ \\
\hline
\end{tabular}

MEP = motor evoked potential; LA-FA = left arterial to femoral artery; DHCA = Deep hypothermic circulatory arrest.

in the published literature $[12,13]$. Mr. Kuduvalli presented the Liverpool data for ATAD. Since 1998, 147 patients have been admitted to the Liverpool Heart and Chest Hospital with Type A dissection. Since 2007, after reorganization of the aortic specialty service, the overall mortality was reduced from $21.0 \%$ to $10.4 \%$. Of the 116 survivors at the unit, $12.1 \%$ of patients had a reintervention. Type of reintervention is displayed in Table 4. The overall in-hospital mortality at Liverpool Heart and Chest Hospital of patients undergoing reintervention following acute Type A dissection is $14.2 \%$. Of this group, those who had reintervention on the reconstructed aortic root and suspended valve had an in-hospital mortality of $7.6 \%$.

\section{Aortic Arch Session}

Dr. Coselli summarized the techniques and outcomes in aortic arch surgery during his presentation at the symposium. He indicated that attempts to repair or replace fusiform aneurysms for the aortic arch began in 1951. Barriers to success included left ventricular strain and atrial fibrillation, plus the risk of catastrophic cerebral ischemia. None of the early attempts were successful until 1957, when De Bakey and colleagues [14], using an early form of antegrade cerebral perfusion, repaired the aortic arch of a 56-year-old patient by replacing it with a homograft. In the 1960s and 1970s, repair progressed with the introduction of the island patch reattachment strategy for the brachiocephalic arteries, the use of profound hypother- 


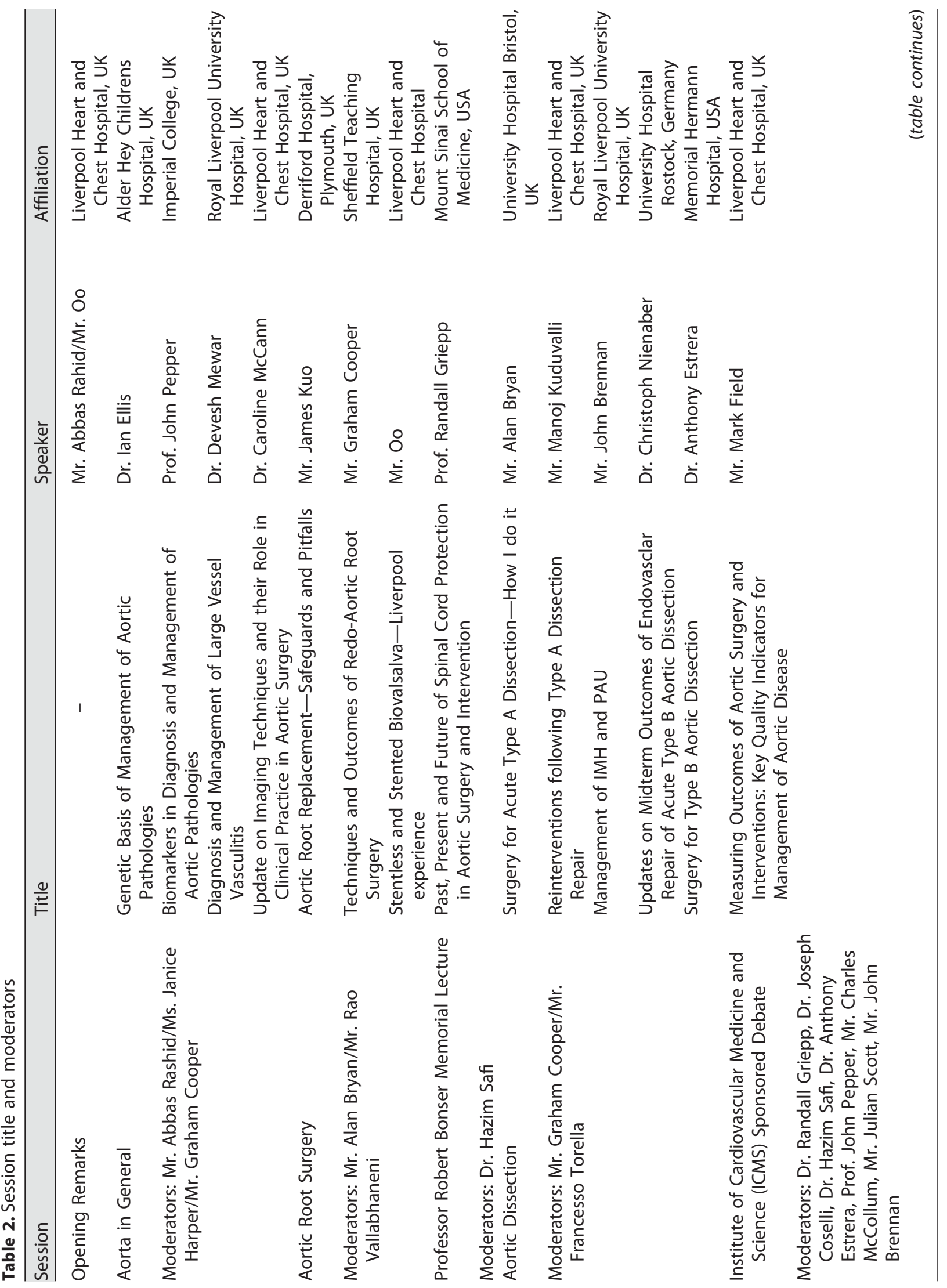




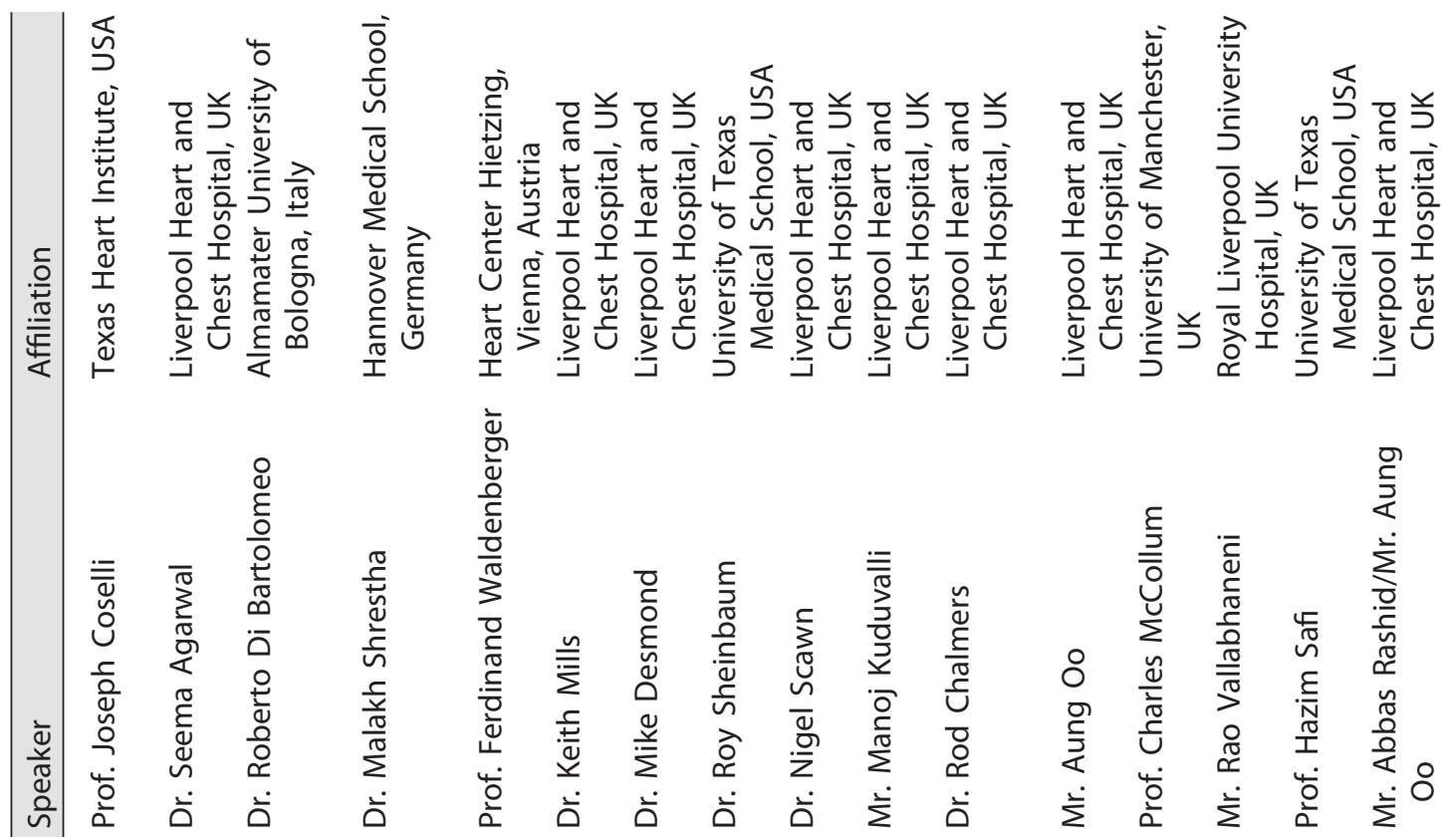

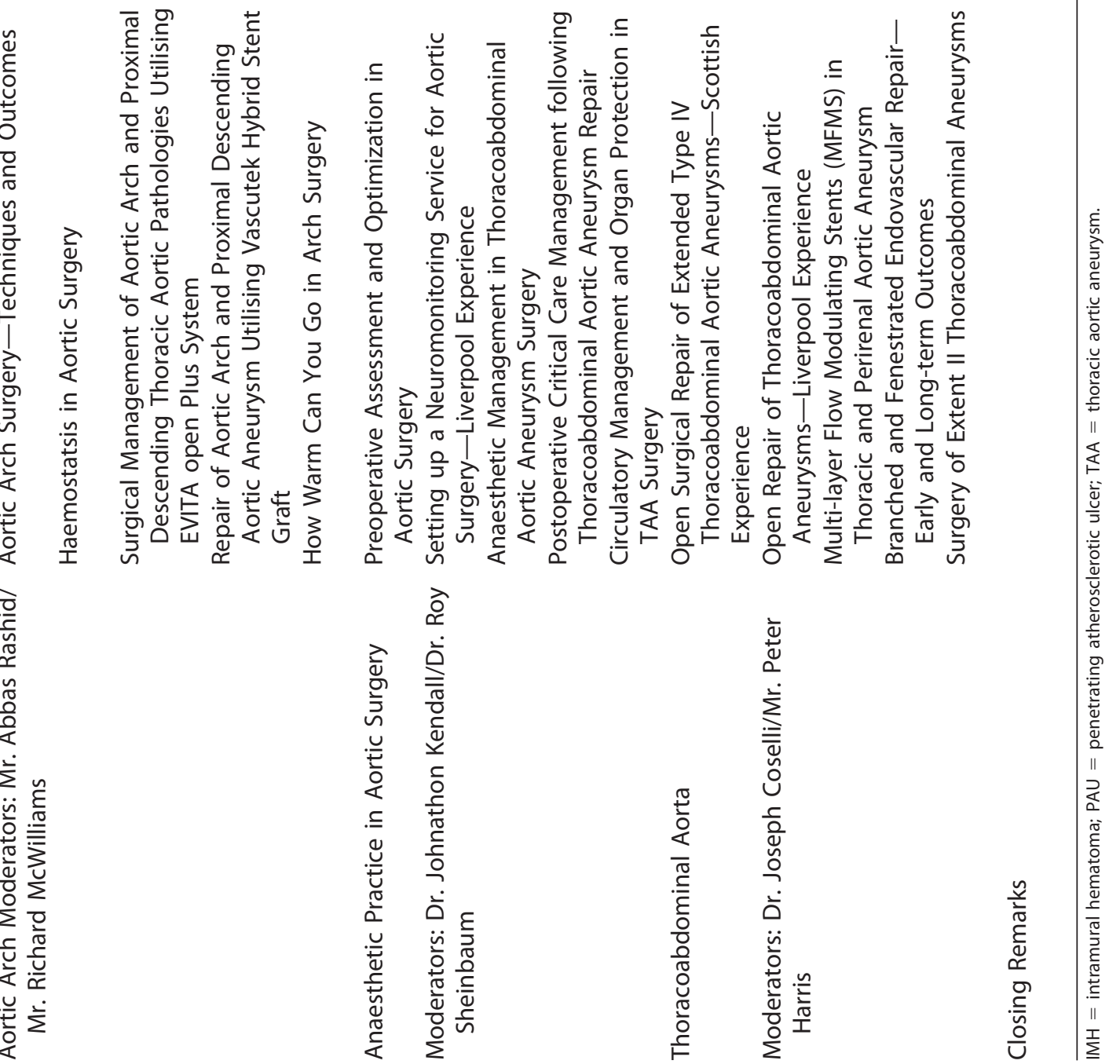


Table 3. Indications in the Literature for Reoperative Aortic Root Replacement Based on Series of Heterogeneous Case Reviews [4-11]

\begin{tabular}{lcc}
\hline Indications & Frequency From & To \\
\hline Infection & $4 \%$ & $50 \%$ \\
Valve dysfunction & $18 \%$ & $55 \%$ \\
False aneurysm & $2 \%$ & $50 \%$ \\
True aneurysm & $25 \%$ & $83 \%$ \\
Acute dissection & $3 \%$ & $8 \%$ \\
\hline
\end{tabular}

Table 4. Reintervention at Liverpool Heart and Chest Hospital Following Acute Type A Dissection

\begin{tabular}{lc}
\hline Reintervention & $\%$ of Patients \\
\hline Bentall & $14.2 \%$ \\
Bentall + total arch replacement & $14.2 \%$ \\
Arch replacements & $28.5 \%$ \\
Repair of pseudoaneurysm from LCA button & $14.2 \%$ \\
DTA & $7.1 \%$ \\
Extent I TAAA & $7.1 \%$ \\
Extent II TAAA & $7.1 \%$ \\
Distal abdominal aorta & $7.1 \%$ \\
\hline LCA = left coronary artery; DTA = descending thoracic aneurysm; TAAA $=$ thoraco- \\
abdominal aortic aneurysm.
\end{tabular}

mic circulatory arrest $\left(\mathrm{HCA} ; 14^{\circ} \mathrm{C}\right)$, and open distal anastomosis techniques [15]. In the late 1980s and early 1990s, cerebral perfusion strategies were improved to better protect patients from stroke by antegrade and retrograde cerebral perfusion techniques. Cerebral perfusion techniques were explored, flexible cerebral perfusion catheters were developed, and a cold cerebroplegia technique was introduced [16]. In this era, elephant trunk approaches to extensive aortic repair were introduced by Borst et al. [17] as part of a staged repair. The advances of the frozen elephant trunk (FET) have even reduced a two-staged repair to one in selected patients. Spielvogel [18] radically changed aortic arch repair by developing the $Y$ graft approaches, which essentially debranched the brachiocephalic vessels and moved the distal anastomosis forward. With the addition of a collared elephant trunk graft, this technique has been adopted by several centers with good results, even in patients with acute dissection. Most centers use antegrade cerebral perfusion rather than retrograde, and many centers are exploring the use of more moderate temperatures for HCA. Despite this fact, Dr. Waldenberger com-

Aorta, June 2014 mented that the incidence of neurological complications is still considerably high. The brain and spinal cord are both vulnerable to ischemia and hypoxia, the approaches to mitigate the effects of hypoperfusion are numerous, and the knowledge concerning the entire problem is still limited. Accordingly, the optimal temperature for HCA during arch surgery remains unclear. However, temperature management is only one variable in a complex strategy including a myriad of other clinical variables, such as location of temperature measurement, cannulation site, perfusion techniques, and use of intraoperative neuromonitoring. In view of these limitations of circulatory arrest, he reflected the logical evidence, which is to evaluate a normothermic approach to aortic arch surgery. This has become gradually the standard practice in many centers on the basis of superior results obtained due to maintaining patient physiological state during aortic arch surgery [19]. "How warm can we go in aortic arch surgery?" remains an elusive question that is still unanswered in the present era.

Advances in the elephant trunk procedure. The development of the elephant trunk procedure for aneurysm of the ascending, arch, and descending thoracic aorta has improved the repair of complex aortic lesions by facilitating the proximal anastomosis at the time of the second-stage descending aneurysm repair [20]. The second intervention carries the cumulative risk of two major procedures, an additional risk for mortality up to 5\% [8], and a spinal cord injury risk of $3 \%$ to $10 \%$ [21]. This led to the evolution of the FET that summed the aortic repair in one single stage. The Vascutek Hybrid Device (Vascutek Terumo) is designed to further simplify the one-stage FET procedure by providing a one-piece device, thereby removing the need to join the conventional prosthesis and endovascular stent graft [22]. The Vascutek Thoraflex Hybrid Device is a woven polyester prosthesis, with the addition of nitinol ring stents. Branches are provided to accommodate reconstruction of the major aortic branch vessels and intraoperative attachment of a perfusion cannula during cardiopulmonary bypass where antegrade perfusion techniques are employed. In a recent study done by the Hannover group [23], looking at their ten years' experience with the use of FET, they concluded that the FET concept adds to the armamentarium of the surgeon in the treatment of complex and diverse aortic arch pathologies. The preoperative patient risk profile explains the still con- 
Table 5. Liverpool Experience of TAAA Surgical Repair

\begin{tabular}{lc}
\hline Surgery & Number of Patients \\
\hline DTA and TAAA (Extent I-V) & 178 \\
Open surgery & 163 \\
DTA & 33 \\
TAAA I-V & 130 \\
TAAA I & 28 \\
TAAA II & 91 \\
TAAA III & 6 \\
TAAA IV & 5 \\
\hline DTA = descending thoracic aneurysm; TAAA = thoracoabdominal aortic aneurysm.
\end{tabular}

siderable postoperative morbidity and in-hospital mortality. The FET can still potentially be a "onestage" procedure in selected patients. However, the extension of FET to patients with extensive aortic aneurysms has led to an increase in the need for additional procedures.

\section{Past, Present, and Future of Spinal Cord Protection in Aortic Surgery and Intervention.}

Dr. Griepp presented the history of spinal cord protection in aortic surgery; he further shared some experimental data his team is working on during the Robert Bonser Memorial Lecture at the symposium.

He presented a short synopsis on how, traditionally, the spinal cord was thought to be perfused by a single artery, mainly arising from the descending aorta, namely the artery of Adamkiewicz. Dr. Griepp's teams have challenged this view by proposing the existence of an ex-
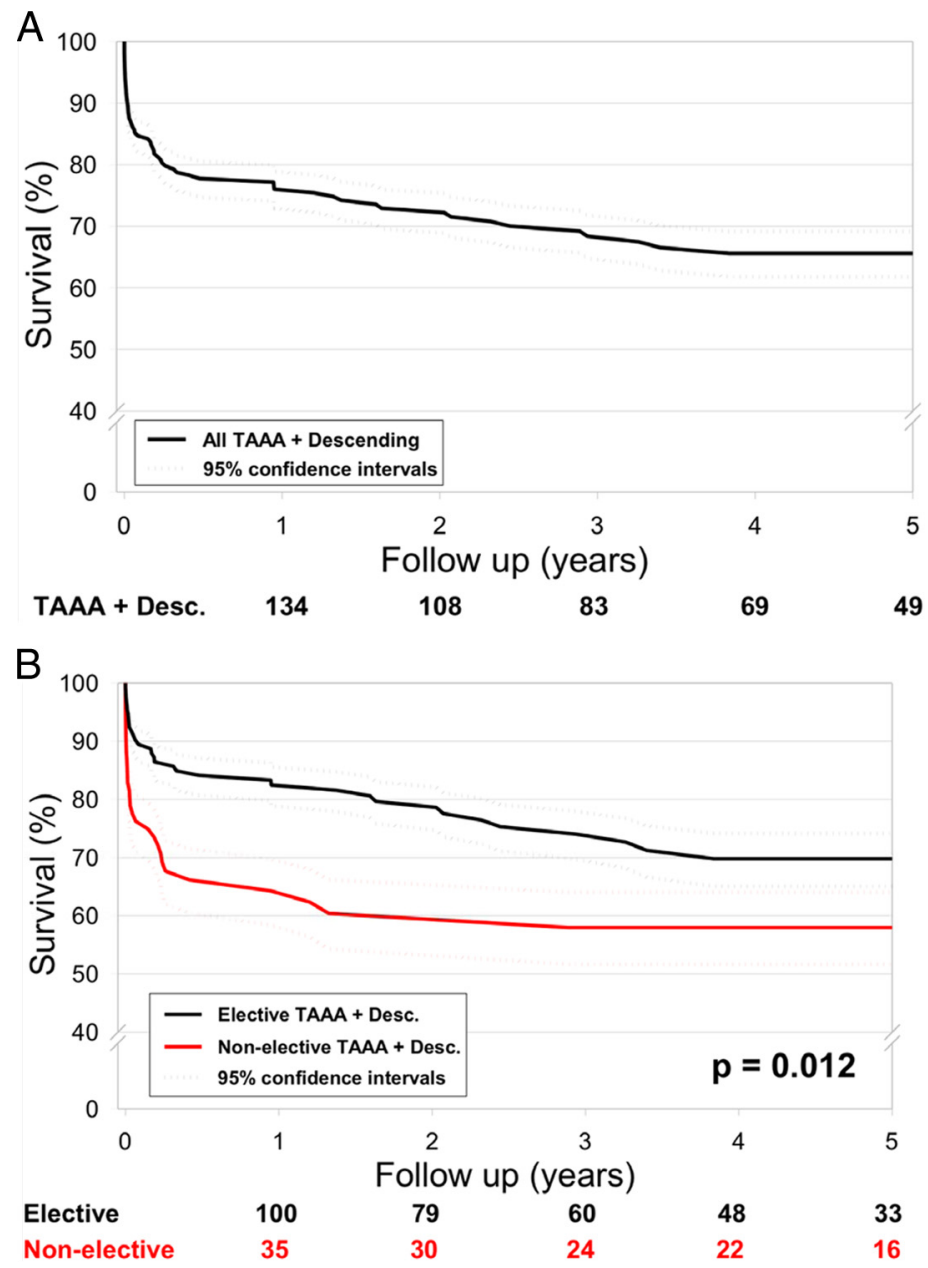

Figure 1. (A) TAAA + descending aortic surgery mid-term survival (note truncated axis). (B) TAAA + descending aortic surgery mid-term survival, stratified by operative priority (note truncated axis). 
tensive collateral network. This collateral network includes all the segmental arteries, both intercostal and lumbar, which send branches to the anterior spinal artery [23]. Griepp and colleagues also propose that the anterior spinal artery is fed by an extensive epidural arterial network, and by a dense array of small vessels which supply the paraspinal musculature. The extensive collateral network allows compensatory flow to the spinal cord when some of the direct inputs to the anterior spinal artery are compromised. Retrospective analysis of extensive thoraco-abdominal repairs has revealed that patients undergoing a two-staged repair compared to those who undergo a single-staged repair had a much lower risk of developing spinal cord injury [24]. It is from this observation that it was it was proposed that physiological adaptations of the collateral network in response to loss of the segmental arteries allowed for better spinal cord perfusion.

This collateral network was visibly demonstrated through a series of anatomical studies of the collateral network wherein casts of methyl methacrylate of the circulatory system of juvenile pigs were made [25]. This showed a vast network of interconnected small arteries and arterioles surrounding the spinal cord: a matrix of vessels connecting the relatively modest spinal cord perfusion circuit with the much more extensive network of vessels supplying the paraspinal muscles. Furthermore, these casts showed that sacrifice of the segmental arteries causes enlargement of the anterior spinal artery after 24 hours, with further expansion of various components of the intraspinal circulation by 5 days. Analysis also reveals that there is a gradual reorientation of proliferating vessels after extensive segmental artery sacrifice to be more parallel to the spinal axis [25].

Further research into the anatomy and physiology of the spinal cord circulation can be helpful in directing the time course of staged interventions and the duration and nature of measures to improve spinal cord protection.

\section{Quality and Outcome}

Quality outcomes for aortic intervention. Quality is dependent on perspective and will be defined differently by patient, provider (hospital versus caregivers), payers/commissioners, and society. We discussed desired outcomes, which center on provision of a triad of prognostic benefit, symptomatic relief, and improved quality of life based on patient-reported outcomes measures (PROMs), delivered in a subspecialized, mul- tidisciplinary, high volume, safe, and cost-effective manner. These factors are considered within the structure of outcome, process, and structure (Donabedian model). At the symposium, Mr. Field presented a number of dimensions including acute and elective services and preoperative, operative, and postoperative processes. Anatomical breakdown such as root surgery, arch surgery, and thoracoabdominal surgery was discussed, as well as endovascular intervention.

Other issues for discussion and inclusion in generic "quality accounts" include: hospital versus team versus individual outcomes, volume, training, technical support, reintervention rate, perfusion, length of stay audit, benchmarking, education, genetic counseling, and imaging follow-up.

\section{Anesthesia and Perfusion}

Setting up a neuromonitoring service for aortic surgery-Liverpool experience. Little if any information exists on the practical issues of setting up such a service, managing patients safely using this technology, and informing potential users of pitfalls and safeguards. The Thoracic Aortic Aneurysm Service at Liverpool Heart and Chest Hospital has been developing a program for intervention on the descending thoracic aorta over the last decade. As part of the introduction of a number of measures to prevent intraoperative paraplegia, we introduced transcranial motor evoked potential (tcMEP) monitoring. Our previous observations had suggested that in a significant proportion of patients, transient paraplegia was not acquired intraoperatively but was delayed (days 1-3) and was often related to deviation from agreed upon postoperative instructions for management of spinal cord perfusion pressure. We therefore extended our use of tcMEP monitoring to the postoperative period on intensive care. This formed processes and protocols for setting up and managing perioperative tcMEP monitoring, in the form of a pathway.

\section{Thoracoabdominal Aortic Surgery}

Open repair of thoracoabdominal aortic aneurysms-Liverpool experience. Open surgical repair of thoracoabdominal aortic aneurysm (TAAA) is not widely performed in the United Kingdom. In Liverpool, the thoracic aortic aneurysm service was developed over the last 17 years. The first open repairs of TAAA took place in 1996. This procedure has evolved over 
the last decade with introduction of a multidisciplinary team approach and an integrated organ protection strategy. From January 1996 to February 2012, 178 descending thoracic aneurysms (DTAs) and TAAAs were treated in Liverpool. A total of 130 patients underwent open repair of TAAA. Mean age was 66 years and $33.9 \%$ were female. Spinal drainage was performed for all patients. Over the last year, MEPs were introduced as routine for intra- and postoperative monitoring. Patients who were suitable for proximal clamping of DTA procedures were operated with distal perfusion via left heart bypass. Those unsuitable for proximal clamping were operated under hypothermic circulatory arrest. Our 30 day mortality in the elective group was $8.3 \%$ and for nonelective was $26.3 \%$. Permanent stroke incidence was $6.1 \%$. Paraplegia occurred in $2.8 \%$ of the elective surgery group. A total of $23.7 \%$ developed respiratory complications and $25 \%$ developed renal failure. The five-year survival of the elective patients is $70 \%$ (Table 5 , Fig. $1 \mathrm{~A}$ and $1 \mathrm{~B}$ ).

\section{Summary}

The Fifth Liverpool Aortic Surgery Symposium was very well accepted from the international audience in attendance. The subtitle of the symposium, "new frontiers," was extremely apt considering the topics of discussion and the presentations given over the course of the two days. The Liverpool Aortic team looks forward to hosting the next Liverpool Aortic Symposium in 2015 and hopes to see you there. More information will be available from http://www.aorticaneurysm.org.uk/ closer to the date of the symposium.

\section{Conflict of Interest}

The authors have no conflict of interest relevant to this publication.

\section{Comment on this Article or Ask a Question}

\section{References}

1. De Paulis R, De Matteis GM, Nardi P, Scaffa R, Colella DF, Chiarello L. A new aortic Dacron conduit for surgical treatment of aortic root pathology. Ital Heart J. 2000;1:457-463.

2. De Paulis R, Scaffa R, Maselli D, Weltert L, Salica A, Bellisario A. Valsalva graft in the Bentall procedure: from mechanical valve to the BioValsalva, world's first biological aortic conduit. Surg Technol Int. 2008;17: 216-221.

3. Girardi LN, Coselli JS. Reoperative repair of the aortic root and ascending aorta. Tex Heart Inst J. 2011;38:680-683.

4. David TE, Feindel CM, Ivanov J, Armstrong S. Aortic root replacement in patients with previous heart surgery. J Card Surg. 2004; 19:325-328. 10.1111/j.0886-0440.2004. 4058_11.x

5. Dougenis D, Daily BB, Kouchoukos NT. Reoperations on the aortic root and ascending aorta. Ann Thorac Surg. 1997;64:986-992. 10.1016/S0003-4975(97)00626-7

6. Kirsch EW, Radu NC, Mekontso-Dessap A, Hillion ML, Loisance D. Aortic root replacement after previous surgical intervention on the aortic valve, aortic root, or ascending aorta. J Thorac Cardiovasc Surg. 2006;131: 601-608. 10.1016/j.jtcvs.2005.11.007

7. LeMaire SA, DiBardino DJ, Köksoy C, Coselli JS. Proximal aortic reoperations in patients with composite valve grafts. Ann Thorac Surg. 2002;
5:S1777-S1782; discussion S-1792-S1799. 10. 1016/S0003-4975(02)04152-8

8. Malvindi PG, van Putte BP, Heijmen RH, Schepens MA, Morshuis WJ. Reoperations on the aortic root: experience in 46 patients. Ann Thorac Surg. 2010;89:81-86. 10.1016/j. athoracsur.2009.09.014

9. Schepens MA, Dossche KM, Morshuis WJ. Reoperations on the ascending aorta and aortic root: pitfalls and results in 134 patients. Ann Thorac Surg. 1999;68:1676-1680. 10.1016/S0003-4975(99)00760-2

10. Szeto WY, Bavaria JE, Bowen FW, Geirsson A, Cornelius K, Hargrove WC, et al. Reoperative aortic root replacement in patients with previous aortic surgery. Ann Thorac Surg. 2007; 84:1592-1598;discussion1598-1599.10.1016/ j.athoracsur.2007.05.049

11. Malvindi PG, van Putte BP, Heijmen RH, Schepens MA, Morshuis WJ. Reoperations on the aortic root: experience in 46 patients. Ann Thorac Surg. 2010;89:81-86. 10.1016/j. athoracsur.2009.09.014

12. Faure EM, Canaud L, Agostini C, Shaub R, Böge $G$, Marty-Ané $C$, et al. Reintervention after thoracic endovascular aortic repair of complicated aortic dissection. J Vasc Surg. 2014;59:327-333. 10.1016/j.jvs.2013.08.089

13. Tan ME, Morshuis WJ, Dossche KM, Kelder JC, Waanders FG, Schepens MA. Long-term results after 27 years of surgical treatment of acute type a aortic dissection. Ann Thorac
Surg. 2005;80:523-529. 10.1016/j.athoracsur. 2005.02.059

14. De Bakey ME, Crawford ES, Cooley DA, Morris GC Jr. Successful resection of fusiform aneurysm of aortic arch with replacement by homograft. Surg Gynecol Obstet. 1957;105: 657-664.

15. Bloodwell RD, Hallman GL, Cooley DA. Total replacement of the aortic arch and the "subclavian steal" phenomenon. Ann Thorac Surg. 1968;5:236-245. 10.1016/S00034975(10)66338-2

16. Coselli JS, LeMaire SA. Aortic arch surgery: principles, strategies, and outcomes. Chichester, UK: Wiley-Blackwell. 2008.

17. Borst HG, Walterbusch G, Schaps D. Extensive aortic replacement using "elephant trunk" prosthesis. Thorac Cardiovasc Surg 1983;31:37-40. 10.1055/s-2007-1020290

18. Spielvogel D, Etz CD, Silovitz D, Lansman SL, Griepp RB. Aortic arch replacement with a trifurcated graft. Ann Thorac Surg 2007;83: S791-S795; discussion S824-S831. 10.1016/ j.athoracsur.2006.11.015

19. Murphy GS, Hessel EA 2nd, Groom RC. Optimal perfusion during cardiopulmonary bypass: an evidence-based approach. Anesth Analg. 2009;108:1394-1417. 10.1213/ane. 0b013e3181875e2e

20. Heinemann MK, Buehner B, Jurmann MJ, Borst H-G. Use of the "elephant trunk technique" in aortic surgery. Ann Thorac Surg. 
1995;60:2-6; discussion 7. 10.1016/500034975(95)00319-3

21. Williams GM, Perler BA, Burdick JF, Osterman FA Jr, Mitchell S, Merine D, et al. Angiographic localization of spinal cord blood supply and its relationship to postoperative paraplegia. J Vasc Surg 1991;13: 23-33; discussion 33-35. 10.1016/07415214(91)90009-J.

22. Shrestha M, Pichlmaier M, Martens A, Hagl C, Khaladj N, Haverich A. Total aortic arch replacement with a novel four-branched frozen elephant trunk graft: first-in-man results. Eur J Cardiothorac Surg. 2013;43:406-410. 10.1093/ejcts/ezs296
23. Griepp EB, Di Luozzo G, Schray D, Stefanovic A, Geisbüsch S, Griepp RB. The anatomy of the spinal cord collateral circulation. Ann Cardiothorac Surg. 2012;1:350-357. 10.3978/ j.issn.2225-319X.2012.09.03

24. Etz CD, Zoli S, Mueller CS, Bodian CA, Di Luozzo G, Lazala R, et al. Staged repair significantly reduces paraplegia rate after extensive thoracoabdominal aortic aneurysm repair. J Thorac Cardiovasc Surg. 2010;139:1464-1472. 10.1016/j.jtcvs.2010. 02.037

25. Etz CD, Kari FA, Mueller CS, Silovitz D, Brenner RM, Lin HM, et al. The collateral network concept: a reassessment of the anat- omy of spinal cord perfusion. J Thorac Cardiovas Surg. 2011;141:1020-1028. 10.1016/j.jtcvs. 2010.06 .023

Cite this article as: Bashir $M$, Fok $M$, Shaw M, Field M, Kuduvalli M, Desmond M, Harrington D, Rashid A, Oo A. Liverpool Aortic Surgery Symposium V: New Frontiers in Aortic Disease and Surgery. Aorta 2014;2(3):100-109. DOI: http://dx. doi.org/10.12945/j.aorta.2014.13-051 